\title{
Dual Frequency CPW Fractal Antenna for Wireless Applications
}

\author{
Krishna Chennakesava Rao M, Pachiyaannan M
}

\begin{abstract}
A Co-planar wave guide fed rectangular ring antenna for WiFi and $5 G$ applications is proposed in this paper. The operating frequency of the antenna is centered at two frequencies i.e $2.52 \mathrm{GHz}$ and $3.65 \mathrm{GHz}$ which are in $S$-band frequency spectrum. The main radiator is rectangular ring for whose inner corners are smoothed. The similar structure of the main radiator is etched from the ground plane making the proposed technique a fractal. For the proposed antenna FR4 laminate is used as substrate and a line feed is used to provide excitation. To achieve the high wide bandwidth we have implemented the fractal technique. The antenna size is $60 \mathrm{~mm} \times 60 \mathrm{~mm} \times 1.6 \mathrm{~mm}$ and is radiating in the frequency range of $2.27 \mathrm{GHz}$ to $2.67 \mathrm{GHz}$ covering $400 \mathrm{MHz}$ of bandwidth and $3.5 \mathrm{GHz}$ to $3.82 \mathrm{GHz}$ covering $320 \mathrm{MHz}$ of bandwidth.
\end{abstract}

\section{Keywords - WiFi, 5G, Fractal, Dual band Applications.}

\section{INTRODUCTION}

To meet the requirement of the modern communication systems the need for antennas with considerable gain and Wide bandwidth of operation is increasing day by day and it has become a challenge for the designers to achieve Wide bandwidth resonance with a considerable gain. For Ku band application compactness is a very essential parameter so that the antenna can be carried easily and can be integrated into any system used for various applications.

In [1] an antenna with wideband resonance has been proposed where the patch has been shorted with the ground using a via for getting wideband resonance but the antenna is fed with a coaxial feed line which will have low radiation efficiency because of the surface waves produced by the feed pin as the feed pin passes through the substrate material. In [2] an antenna with two radiating elements placed on one another using stacked patch technique has been proposed where the authors used two feeds to excite two patches for achieving wideband resonance. But this technique needs two transmitter circuits which will affect the cost of the system and also the size is very high. In [3] an antenna etched with truncations in the corners has been proposed to achieve Wideband resonance but due to the irregular slots in patch the antenna pattern is not uniform and the power coming out from the antenna is not uniform over the entire region.

In this paper, A Co-planar wave guide fed rectangular ring antenna for $\mathrm{WiFi}$ and $5 \mathrm{G}$ applications is proposed.

Revised Manuscript Received on December 15, 2019

Krishna Chennakesava Rao M, Advanced RF Microwave and Wireless Communication Laboratory, Department of Electronics and Communication Engineering Vignan's Foundation for Science, Technology \& Research, Guntur, Andhra Pradesh, India. mkcrao.phd@gmail.com

Pachiyaannan M, Advanced RF Microwave and Wireless Communication Laboratory, Department of Electronics and Communication Engineering Vignan's Foundation for Science, Technology \& Research, Guntur, Andhra Pradesh, India. pachiphd@gmail.com.
To achieve the high wide bandwidth we have implemented the fractal technique. The main radiator is rectangular ring for whose inner corners are smoothed. The similar structure of the main radiator is etched from the ground plane making the proposed technique a fractal.

\section{PROPOSED ANTENNA DESIGN}

Proposed is a Co-planar wave guide fed rectangular ring antenna for $\mathrm{WiFi}$ and $5 \mathrm{G}$ applications is proposed in this paper. The operating frequency of the antenna is centered at two frequencies i.e $2.52 \mathrm{GHz}$ and $3.65 \mathrm{GHz}$ which are in $\mathrm{S}$ band frequency spectrum. The main radiator is rectangular ring for whose inner corners are smoothed. The similar structure of the main radiator is etched from the ground plane making the proposed technique a fractal. For the proposed antenna FR4 laminate is used as substrate and a line feed is used to provide excitation. To achieve the high wide bandwidth we have implemented the fractal technique. The antenna size is $60 \mathrm{~mm} \times 60 \mathrm{~mm} \times 1.6 \mathrm{~mm}$ and is radiating in the frequency range of $2.27 \mathrm{GHz}$ to $2.67 \mathrm{GHz}$ covering $400 \mathrm{MHz}$ of bandwidth and $3.5 \mathrm{GHz}$ to $3.82 \mathrm{GHz}$ covering $320 \mathrm{MHz}$ of bandwidth. The optimized dimensions of the antenna are given as $A=60 \mathrm{~mm}, B=60 \mathrm{~mm}, C=4 \mathrm{~mm}$, $\mathrm{D}=37 \mathrm{~mm}, \mathrm{E}=22 \mathrm{~mm}, \mathrm{~F}=5 \mathrm{~mm}$ as shown in the figure 1 below.

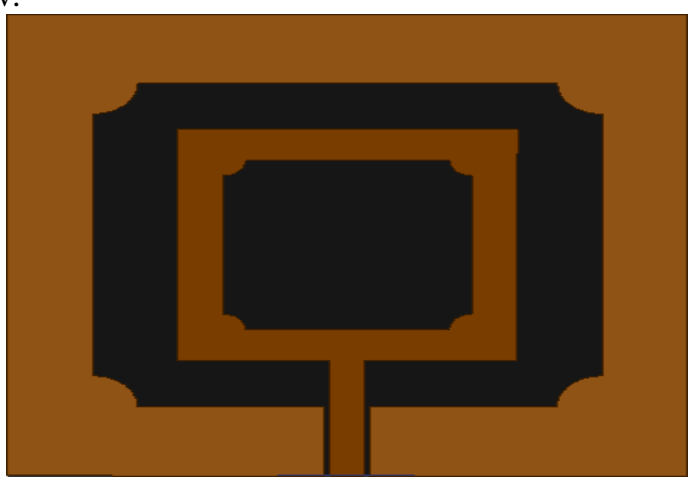

(a) Top View

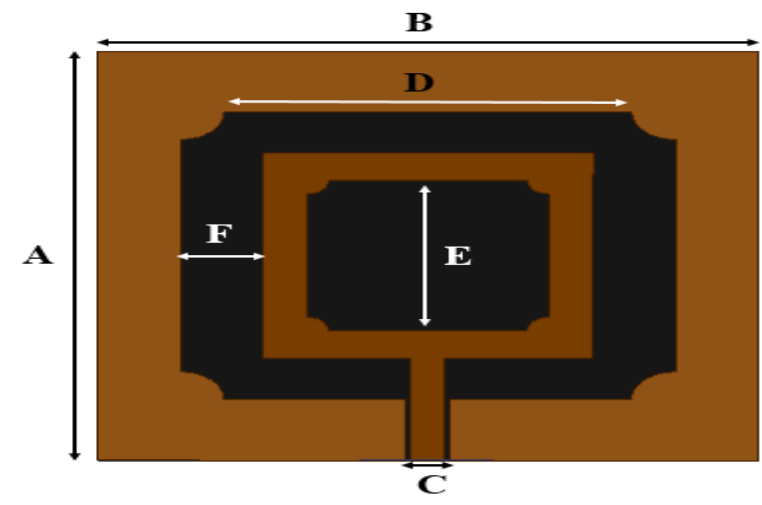

(b) Schematic view

Fig. 1. Antenna Model

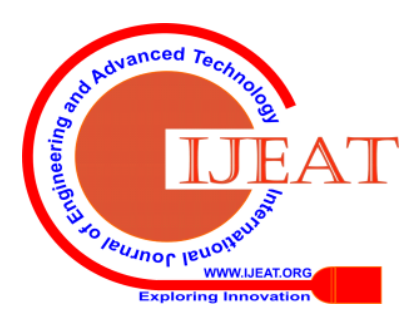




\section{Dual Frequency CPW Fractal Antenna for Wireless Applications}

\section{RESULTS}

The performance of the antenna is measured by analyzing various parameters which includes impedance matching and radiation characteristics. Under impedance matching we will verify two parameters namely return loss also called as $S_{11}$ and Voltage standing wave ratio which is simply called as VSWR. [4-7]. From Figure 3 below we can see that the antenna is radiating in the frequency range of $2.27 \mathrm{GHz}$ to $2.67 \mathrm{GHz}$ covering $400 \mathrm{MHz}$ of bandwidth and $3.5 \mathrm{GHz}$ to $3.82 \mathrm{GHz}$ covering $320 \mathrm{MHz}$ of bandwidth.

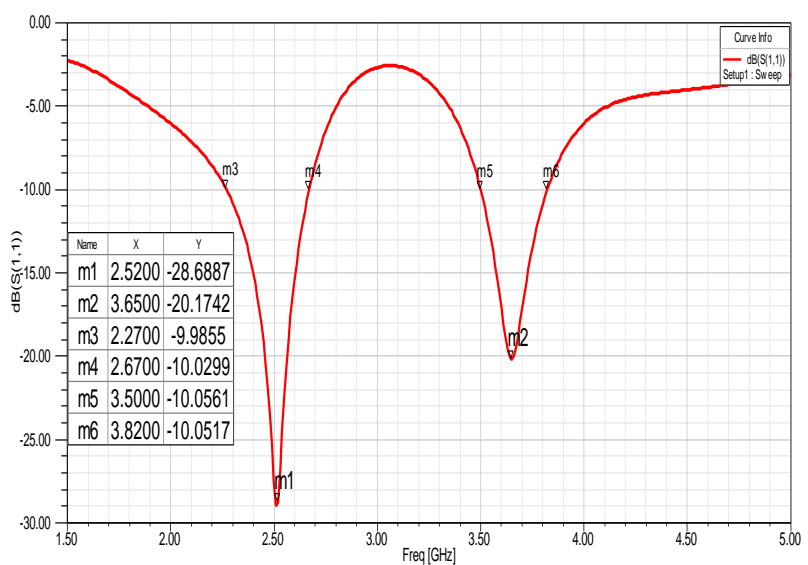

Fig. 2. Return loss

From Figure 4 below we can see that the antenna is radiating in the frequency range of $2.27 \mathrm{GHz}$ to $2.67 \mathrm{GHz}$ covering $400 \mathrm{MHz}$ of bandwidth and $3.5 \mathrm{GHz}$ to $3.82 \mathrm{GHz}$ covering $320 \mathrm{MHz}$ of bandwidth.

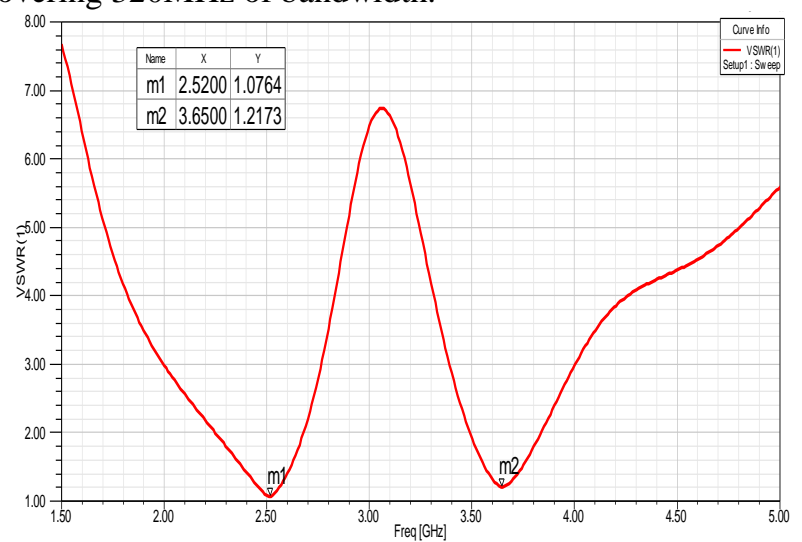

Fig. 3. VSWR

Proposed antenna is having a gain of $3.98 \mathrm{~dB}$ and $4.33 \mathrm{~dB}$ at $2.52 \mathrm{GHz}$ and $3.65 \mathrm{GHz}$ respectively which are shows in the figures 4,5 below.

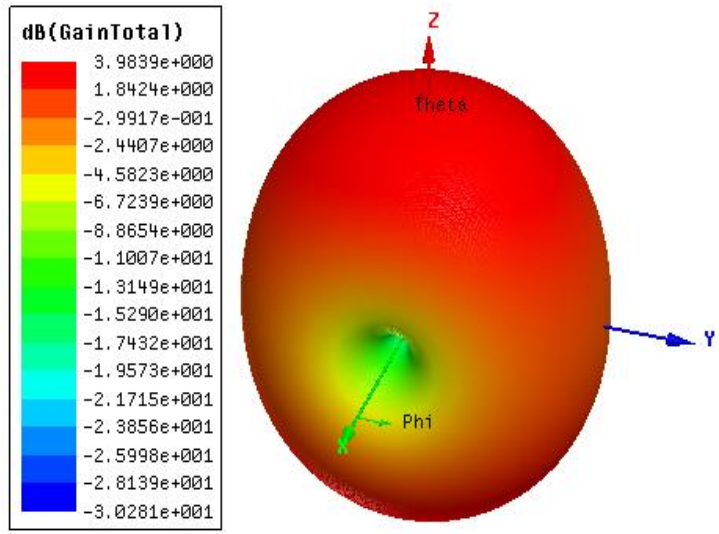

Fig.4. Gain at $2.52 \mathrm{GHz}$
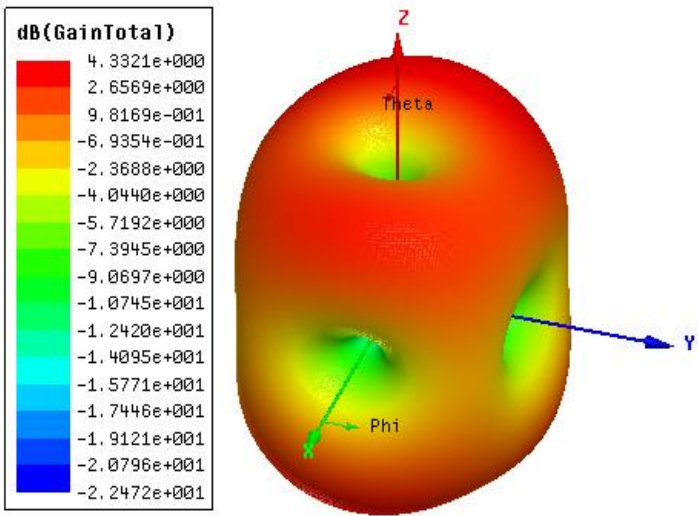

Fig. 5. Gain at 3.65 GHz

The far field radiation characteristics at the two center frequencies of $2.52 \mathrm{GHz}$ and $3.65 \mathrm{GHz}$ are shown below in Figures 7 and 8 . To analyze the radiation characteristics of the antenna we need to check both the elevation plane and azimuthal planes. Both the patterns are having uniform distribution of the power in different theta angles without any nulls which is very essential for the wireless applications for proper planning of the antenna coverage area.

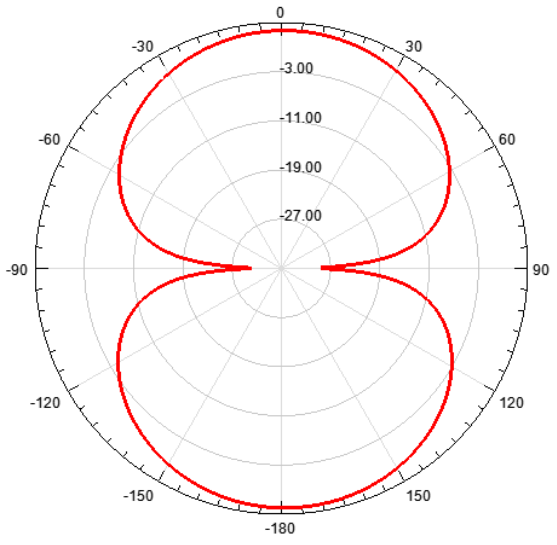

(a) E Plane

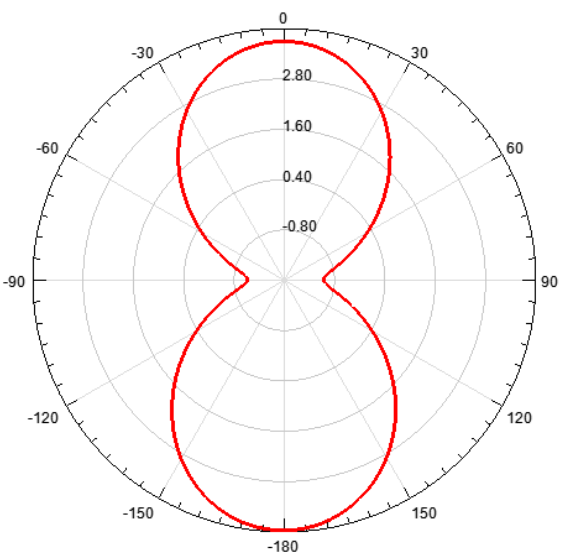

(b) H Plane

Fig. 6. At 2.52GHz 


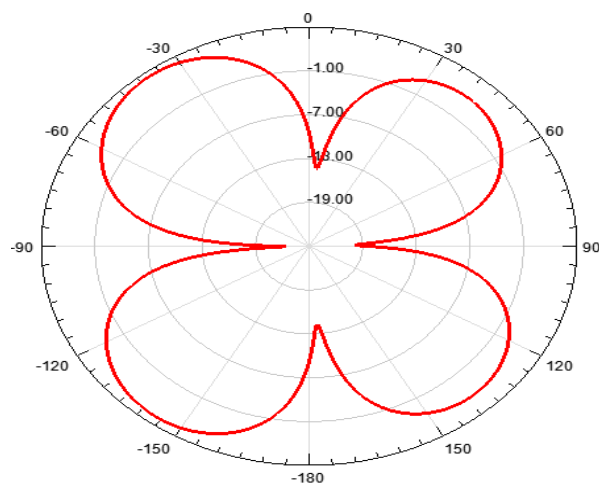

(a) E Plane

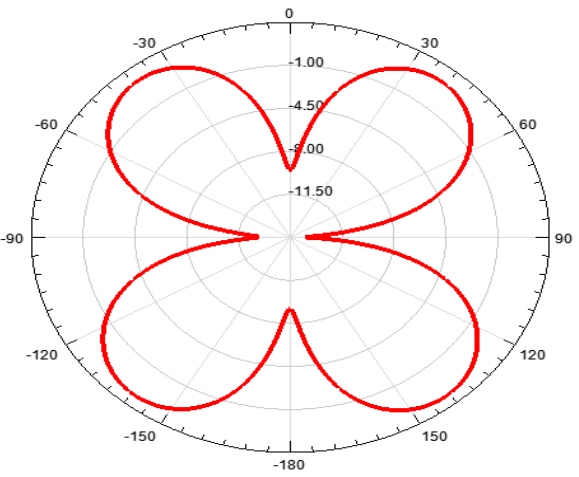

(b) H Plane

Fig. 7. At $3.65 \mathrm{GHz}$

The radiation of the antenna depends on the current fields as shown in the figure 11 below. We can observe that the intensity of the current field is minimum at the center of the patch and maximum at the edges.

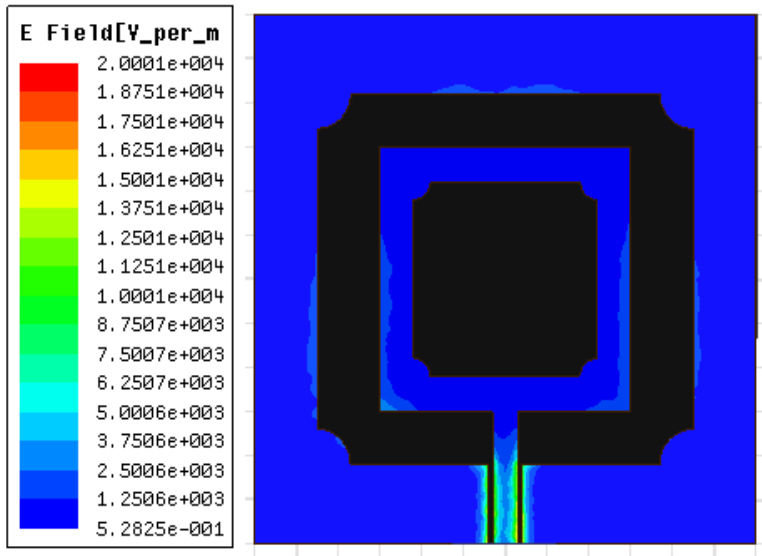

(a) lower patch at $2.52 \mathrm{GHz}$

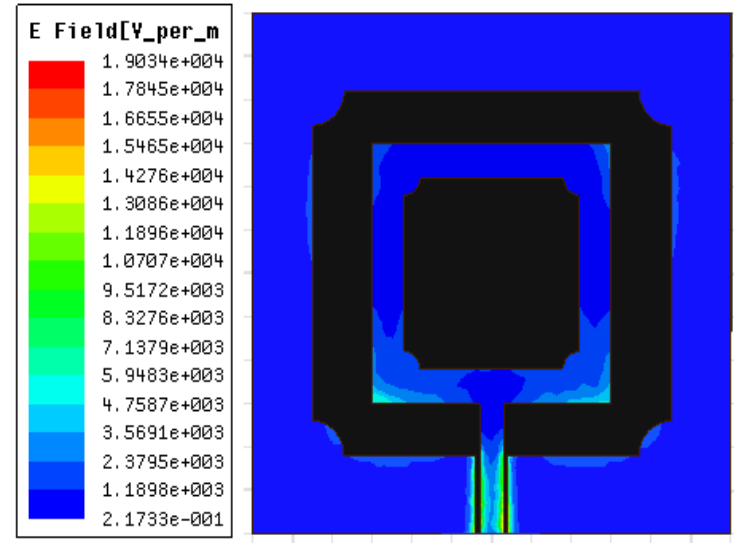

(b) Upper patch at $3.65 \mathrm{GHz}$

Fig. 8. Current distributions of the patch

\section{CONCLUSION}

A Co-planar wave guide fed rectangular ring antenna for $\mathrm{WiFi}$ and $5 \mathrm{G}$ applications is proposed. The operating frequency of the antenna is centered at two frequencies i.e $2.52 \mathrm{GHz}$ and $3.65 \mathrm{GHz}$ which are in S-band frequency spectrum. The main radiator is rectangular ring for whose inner corners are smoothed. The similar structure of the main radiator is etched from the ground plane making the proposed technique a fractal. For the proposed antenna FR4 laminate is used as substrate and a line feed is used to provide excitation. To achieve the high wide bandwidth we have implemented the fractal technique. The antenna size is $60 \mathrm{~mm} \times 60 \mathrm{~mm} \times 1.6 \mathrm{~mm}$ and is radiating in the frequency range of $2.27 \mathrm{GHz}$ to $2.67 \mathrm{GHz}$ covering $400 \mathrm{MHz}$ of bandwidth and $3.5 \mathrm{GHz}$ to $3.82 \mathrm{GHz}$ covering $320 \mathrm{MHz}$ of bandwidth.

\section{REFERENCES}

1. E. Kusuma Kumari, A.N.V.Ravi Kumar. (2017). Wideband HighGain Circularly Polarized Planar Antenna Array for L Band Radar IEEE International Conference on Computational Intelligence And Computing Research, Tamilnadu College of Engineering. Tamil Nadu.

2. E. Kusuma Kumari, A.N.V.Ravi Kumar. (2017). Development of an L Band Beam Steering Cuboid Antenna Array. IEEE International Conference on Computational Intelligence And Computing Research, Tamilnadu College of Engineering. Tamil Nadu.

3. Sunkaraboina Sreenu, Vadde Seetharama Rao. (2017). Stacked Microstrip Antenna For Global Positioning System. IEEE International Conference on Computational Intelligence And Computing Research, Tamilnadu College of Engineering. Tamil Nadu.

4. Rao N.A, Kanapala S. (2018). Wideband Circular Polarized Binomial Antenna Array for L-Band Radar. Panda G., Satapathy S., Biswal B., Bansal R. (eds) Microelectronics, Electromagnetics and Telecommunications. Lecture Notes in Electrical Engineering, vol 521. Springer, Singapore.

5. Kanapala S, Rao N.A. (2018). Beam Steering Cuboid Antenna Array for L Band RADAR. Panda G., Satapathy S., Biswal B., Bansal R. (eds) Microelectronics, Electromagnetics and Telecommunications. Lecture Notes in Electrical Engineering, vol 521. Springer, Singapore.

6. Sunkaraboina Sreenu, P. Gnanasivam, M. Sekhar (2018). Circular polarised Antenna Array for C Band Applications. Journal of Advanced Research in Dynamical \& Control Systems, Vol. 10, 14Special Issue.

7. K. Ashwini, M. Sekhar, Sunkaraboina Sreenu. (2018). Mutual Coupling Reduction Using Meander Square EBG Structures for CBand Radars. Journal of Advanced Research in Dynamical \& Control Systems, Vol. 10, 12-Special Issue.

8. Sekhar M, S Naga Kishore B, Siddaiah P. (2014). Triple Frequency Circular Patch Antenna. IEEE International Conference on Computational Intelligence And Computing Research, Park College Of Engineering And Tekhnology. Tamil Nadu.

9. J Lavanya, S Nagakishore Bhavanam, Vasujadevi Midasala "Design of Spiral Antenna for Multiband Applications" International Journal of Innovative Technology and Exploring Engineering, Volume-8 Issue-5 March, 2019. 